\title{
DE MENINA E DE MENINO: A INFLUÊNCIA DE PAIS E FAMILIARES NA SEGREGAÇ̃̃O DE BRINQUEDOS E BRINCADEIRAS POR GÊNERO
}

\author{
GIRL AND BOY: THE INFLUENCE OF PARENTS AND \\ RELATIVES ON THE SEGREGATION OF TOYS AND GAMES BY GENDER
}

\section{RESUMO}

Os brinquedos e as brincadeiras são diferentes para meninas e meninos e insinuam habilidades e papéis sociais desiguais. O objetivo deste estudo foi analisar se a escolha dos brinquedos e brincadeiras de crianças é influenciada pelos seus responsáveis de acordo com o seu sexo biológico e o gênero que estes entendem como correspondente. A pesquisa foi realizada com dezessete pais ou familiares de crianças que estavam matriculadas e frequentes em uma escola municipal da cidade de Pelotas-RS. Os dados foram coletados através de um questionário autoaplicável e sua análise deuse a partir da técnica de análise de conteúdo proposta por Bardin. $\mathrm{O}$ estudo sugere que os pais e familiares de crianças influenciam nas suas escolhas de brinquedos e brincadeiras. O Terapeuta Ocupacional pode minimizar possíveis prejuízos no desempenho ocupacional de crianças no que se refere ao uso dos brinquedos e brincadeiras sem restrições ao gênero.

Palavras-chave: Brinquedo. Brincadeira. Gênero. Criança. Responsáveis. Terapia Ocupacional.

\begin{abstract}
Toys and games are different for girls and boys and imply unequal social skills and roles. The purpose of this study was to analyze whether the choice of toys and games of children is influenced by their responsible caretakers according to their biological sex and the gender they understand as correspondent. The research was performed with seventeen parents or relatives of children who were enrolled and attending a municipal school in the city of Pelotas-RS. Data were collected through a selfadministered questionnaire and its analysis was based on the technique of content analysis proposed by Bardin. The study suggests that parents and family members of children influence their choices of toys and games. The Occupational Therapist can minimize possible losses in the occupational performance of children regarding the use of toys and games without restrictions to the gender.
\end{abstract}

Keywords: Toy. Game. Gender. Child. Responsible. Occupacional Therapy.

Júlia T. Bandeira

UFPEL. Email: juliatband@yahoo.com.br

Camilla O da Costa

UFPEL. Email: camillaoleiro@hotmail.com 


\section{Introdução}

O brincar, conforme Santos et al. (2006), é uma atividade fundamental e indispensável para o desenvolvimento infantil. Para Araújo \& Galvão (2014: 335) é por meio desta atividade que a criança "descobre o mundo ao seu redor, se descobre, experimenta e aprende; localiza-se do ponto de vista social, aprende a dividir, a discordar e a entrar em contato com os outros e se relacionar". À medida que brinca, a criança é estimulada em seus aspectos físicos, sociais e psíquicos (Bicalho, 2013), tem possibilidade de experimentar diferentes sensações e sentimentos (Ferland, 2006), além de vivências importantes, que contribuirão em todas as etapas da sua vida (Maluf, 2009).

As questões culturais, familiares, educacionais e de mercado interferem nas relações das crianças com os brinquedos, sinalizando como, onde e com quem se deve brincar (Lira, 2009). Esses objetos são carregados de expectativas, simbologias e intenções (Finco, 2010) e evidenciam os papéis e condutas esperados sobre como ser mulher ou homem. Segundo Lira \& Nunes (2016: 191) se por um lado os brinquedos das meninas privilegiam "o espaço familiar, a maternidade, a interioridade do lar", os dos meninos priorizam "o mundo do trabalho, da aventura, contextos para além dos muros da casa”.

Conforme Silva \& Brabo (2016), a dicotomia entre sexo/gênero, o estabelecimento de regras ideais de conduta e dos comportamentos próprios da mulher e do homem, são apresentados para a criança, primeiramente, pela família. São os pais quem escolhem os brinquedos dos filhos na primeira infância (Brougére, 1999, apud Sant'anna, 2014) e, por conseguinte, são eles e os familiares os principais responsáveis na distinção de brinquedos e brincadeiras divididas por estereótipos, com diferenciação de objetos e cores próprios para cada gênero (Lamas, 2016).

Lira \& Nunes (2016) estabelecem que os brinquedos são carregados de significações sobre ser mulher e homem, com papéis e condutas esperadas para cada sexo; o que provoca distinções de gênero, que é propiciada primeiramente pelos pais e familiares, acarretando em desigualdades que limitam brincadeiras, aprendizados e oportunidades de pensar e experimentar os diferentes papéis sociais (Lamas, 2016).

Para Carleto et al. (2010) a área de desempenho do brincar é um foco de intervenção dos Terapeutas Ocupacionais; a atividade possibilita aquisição de habilidades, capacidades e competências, sendo, conforme Zen \& Omairi (2009), a principal ocupação na infância e essencial na vida de qualquer indivíduo.

O brincar fornece à criança um domínio sobre o seu próprio corpo e sobre o ambiente, favorecendo o desenvolvimento da integração sensorial, de habilidades físicas e cognitivas e do relacionamento interpessoal. Por meio do brincar, a criança aprende a se expressar, pratica regras culturais e adultas e aprende a se transformar em um membro produtivo da sociedade (Knox \& Mailloux, 1997, apud Martini, 2010: 27). 
A pesquisa se justifica porque os brinquedos são objetos fundamentais para o desenvolvimento dos infantes, e que por serem ofertados diferentemente para meninas e meninos, insinuam habilidades e papéis sociais distintos. $\mathrm{O}$ objetivo foi analisar se os brinquedos e as brincadeiras de crianças são influenciados pelos seus pais ou demais familiares, de acordo com o sexo biológico delas e o gênero que lhes é atribuído.

\section{Métodos}

O artigo é parte integrante de um projeto de pesquisa - trabalho de conclusão de curso de graduação de Terapia Ocupacional da Universidade Federal de Pelotas realizado no período de 2017-2018, intitulado "Brinquedos e brincadeiras: A influência de pais e familiares na segregação por gênero" e que buscou investigar, em uma escola municipal de educação infantil, as possíveis influências de pais ou familiares na escolha de brinquedos e brincadeiras das crianças sob a perspectiva do Terapeuta Ocupacional.

Após as aprovações da Secretaria de Educação e Desporto e do Comitê de Ética em Pesquisa com Seres Humanos (CAAE: 81406817.9.00oo.5317) da Faculdade de Medicina da Universidade Federal de Pelotas - UFPel, obteve-se autorização da escola para a realização da pesquisa. Foi pego a listagem de todas as crianças com idades entre quatro e seis anos, matriculadas e frequentes no turno da manhã e realizado um sorteio (separado por idade e por sexo) para a seleção da amostra, escolhida por conveniência. Assim, foram sorteados vinte responsáveis de crianças e, como o número após o retorno dos questionários foi insatisfatório, foram sorteados mais dez suplentes, os quais integram a amostra do estudo. A escola forneceu o contato telefônico daqueles que foram sorteados.

Para a coleta de dados, foram utilizados dois questionários, contendo questões abertas e fechadas, os quais foram elaborados pela pesquisadora. O primeiro, sociodemográfico, com questões referentes ao responsável da criança (ex.: sexo, idade, situação conjugal, escolaridade, renda familiar). O segundo tratou sobre os brinquedos e brincadeiras que as crianças brincam em seu domicílio (ex.: quais brinquedos/ brincadeiras que a criança mais brinca, quais brinquedos eram comprados para a criança antes de ela começar a pedir). Ambos os questionários eram autoaplicáveis, com um tempo médio de trinta minutos. Aqueles que aceitaram participar da pesquisa preencheram os questionários - juntamente com o Termo de Consentimento Livre e Esclarecido, a qual atendeu todas as necessidades da Resolução 466/2012 - em seu domicílio. Os documentos foram entregues aos participantes pelas crianças, que guardaram os envelopes nas suas mochilas (com auxílio da professora) e deveriam retorna-los à escola por um período máximo de uma semana. As pesquisadoras se coloram a disposição para sanar possíveis esclarecimentos. 
Os dados qualitativos foram analisados através da técnica de análise de conteúdo proposta por Bardin (2016), e após as devidas etapas - pré-análise, exploração do material e tratamento dos resultados, inferência e interpretação -, agrupouse os dados nas três seguintes categorias: brinquedos e brincadeiras de meninas e meninos; sociedade, cultura, mídia e publicidade; e gênero. Os participantes foram identificados com algarismos arábicos de um a dezessete (precedidos pela letra "P") e as falas apresentadas nas categorias corresponderam a uma ou mais respostas dadas pelos responsáveis e que ilustraram a situação de modo mais satisfatório.

\section{Resultados e discussão}

Participaram do estudo dezessete responsáveis - treze mães, três pais e uma avó. Dos trinta sorteados (sendo estes, os vinte primeiros mais os dez suplentes), houve uma exclusão, quatro recusas e oito perdas. A exclusão ocorreu devido à presença de respostas ilegíveis e incompletas. Em relação às recusas, duas foram feitas no primeiro contato com os responsáveis e duas após terem contato com os questionários.

Com relação às características das crianças, nove eram do sexo feminino e oito do sexo masculino; nove possuíam cinco anos e oito possuíam quatro anos. Já sobre o perfil dos pais e familiares, observou-se que quatorze foram do sexo feminino e três foram do sexo masculino. A mediana das idades foi de trinta e três anos.

Percebe-se que a maioria da amostra foi composta por mães, seguido por pais e apenas a presença de uma avó. Em concordância com Arruda \& Lima (2013), o fato das mães corresponderem a maior parte da amostra pode ser justificado porque o cuidado com a educação dos filhos ainda é de responsabilidade da mulher. Para os mesmos autores, se por um lado a sociedade pressiona o homem a se envolver mais - com e em relação aos filhos - em contrapartida, discrimina-o se ele precisar se ausentar do trabalho para se envolver na educação dos mesmos. Vale ressaltar também, que dos três pais que fizeram parte da amostra, apenas um deles convivia em conjunto com uma figura feminina. Os outros dois pais não possuíam tal figura como integrante da família. Pode-se pensar então, que estes pais preencheram os questionários justamente por serem os principais (ou únicos) responsáveis da criança, ao invés das mães - já que estas não são constituintes destes arranjos familiares.

\section{Brinquedos e brincadeiras de meninas e meninos:}

O brinquedo, um objeto atribuído com fortes valores culturais, é utilizado como suporte nas brincadeiras e caracteriza-se por não possuir regras (Kishimoto, 1994). Pode ser qualquer objeto que a criança utilize em suas atividades lúdicas, independente da sua forma, cor ou tamanho. Eles são classificados em estruturados 
- quando possuem obrigatoriamente uma forma ou tamanho definido, como bolas, blocos de montar, chocalhos e cubos de encaixe, por exemplo - e em não estruturados quando não possuem uma identidade e uma função evidente (Ferreira, 1992). Barreto \& Silvestri (2006: 3) afirmam que, em geral, os objetos "permitem a dramatização criativa do cotidiano, a reprodução e a recriação de situações de vida, movimentando uma infinita multiplicidade de valores sociais".

Quadro 1 - Distribuição dos brinquedos por gênero.

\begin{tabular}{|c|c|c|c|}
\hline \multicolumn{5}{|c|}{ BRINQUEDOS } \\
\hline MENINAS & TOTAL & MENINOS & TOTAL \\
\hline Boneca & 8 & Carrinho & 6 \\
\hline Panelinhas/Comidinha & 4 & Blocos de Montar & 3 \\
\hline Bola & 2 & Boneco & 2 \\
\hline Jogo da Memória & 1 & Quebra-Cabeça & 2 \\
\hline Carrinho de Boneca & 1 & Bichos de Pelúcia & 1 \\
\hline Corda de Pular & 1 & Comidinha & 1 \\
\hline & & Bola & 1 \\
\hline
\end{tabular}

Fonte: Elaborado pelas autoras, a partir das respostas dadas pelos responsáveis.

No que concerne aos brinquedos das meninas e dos meninos, nota-se nitidamente a diferenciação dos objetos em relação aos gêneros. As crianças, em geral, possuem mais brinquedos estruturados; possibilitando que a distinção de seus objetos por gênero seja mais evidente. $\mathrm{O}$ brinquedo mais citado, pelos responsáveis das meninas, foi a boneca $(n=8)$. Apenas uma menina não costuma brincar com esse brinquedo. Os conjuntos de panelinhas e comidinhas são os segundos tipos de brinquedos mais utilizados pelas crianças dessa amostra $(n=4)$. Já o brinquedo mais citado pelos responsáveis dos meninos foi o carrinho $(n=6)$, seguido pelos blocos de montar $(\mathrm{n}=3)$. Verifica-se que as meninas não possuem, em sua caixa de brinquedos, carrinhos - apenas os de boneca - nem blocos de montar, e os meninos não usufruem bonecas - apenas bonecos caracterizados como figuras de ação -, tampouco possuem conjuntos de panelinhas e comidinhas, com exceção de um menino que possui somente conjuntos de comidinhas.

Os brinquedos tradicionais de meninas e meninos oportunizam exploração, manipulação, movimento, negociação, sentimento e comunicação; porém possuem tendência a aperfeiçoar, uns mais que outros, algumas habilidades mentais. Bonecas, conjunto de panelinhas e comidinhas promovem capacidades de cuidar dos outros e de sentir empatia para que com eles. Por sua vez, os carrinhos e blocos de montar propiciam capacidades motoras amplas, espaciais e visuais. Se as meninas brincarem somente com os brinquedos ditos de meninas, da mesma forma que os meninos brincarem somente com os brinquedos ditos de meninos, acabarão fortalecendo sempre e exclusivamente as mesmas áreas cerebrais, que no final do período pré- 
escolar já começam a divergir (Eliot, 2013). Sendo assim, é indispensável que a criança possua brinquedos que propiciem objetivos variados; de afeto, como o bicho de pelúcia e a boneca; os que favorecem brincadeiras ao ar livre, como a bola e a bicicleta; os de faz-de-conta, como fantasias e os objetos que imitam profissões de adultos; e os de brincar sozinho, como os blocos de montar e a pintura (Silva, 2008).

A brincadeira é uma atividade lúdica individual ou coletiva que possui estruturação e regras (Kishimoto, 1994). Está diretamente relacionada aos brinquedos, porém está além, pois é capaz de modificar o sentido destes. Através da brincadeira, a criança vive e aprende sobre a sua cultura; ela se apropria da brincadeira conforme a educação que recebe, as referências que possui e os desejos que exprime (Brougère, 2010).

Quadro 2 - Distribuição das brincadeiras por gênero.

\begin{tabular}{|c|c|c|c|}
\hline \multicolumn{5}{|c|}{ BRINCADEIRAS } \\
\hline MENINAS & TOTAL & MENINOS & TOTAL \\
\hline Casinha & 6 & Jogos Eletrônicos & 5 \\
\hline Esconde-Esconde & 4 & Andar de Bicicleta & 5 \\
\hline Pega-Pega & 3 & Jogar Futebol & 4 \\
\hline Jogos Eletrônicos & 3 & Esconde-Esconde & 4 \\
\hline Andar de Bicicleta & 2 & Pega-Pega & 2 \\
\hline Escolinha & 1 & Que envolvam água & 2 \\
\hline Pintar (livros) & 1 & Casinha & 1 \\
\hline Pular na Cama & 1 & Corrida & 1 \\
\hline Jogar Futebol & 1 & Roda Caixinha & 1 \\
\hline Jogar Bola & 1 & Jogar Taco & 1 \\
\hline & & Tocar Instrumentos & 1 \\
\hline & & Profissão de Barbeiro & 1 \\
\hline
\end{tabular}

Fonte: Elaborado pelas autoras, a partir das respostas dadas pelos responsáveis.

No que tange às brincadeiras das meninas e dos meninos, nota-se a existência de brincadeiras consideradas típicas quanto aos gêneros e as que são comuns entre os dois sexos. A brincadeira mais citada, pelos responsáveis das meninas, foi a de casinha $(n=6)$. Já a dos meninos, variou entre jogos eletrônicos $(n=5)$ e andar de bicicleta $(n=5)$.

Percebe-se também, nas brincadeiras, a existência de transgressões, onde duas crianças ultrapassam as fronteiras de gênero, confrontando os padrões préestabelecidos, na qual uma menina costuma jogar futebol - característico como uma atividade típica masculina - e um menino costuma brincar de casinha - característico como uma atividade típica feminina. Apesar dos meios em que as crianças estão inseridas serem dotados de uma carga de estereótipos, as meninas e os meninos são capazes de burlar as ideias do que é considerado típico feminino ou masculino, escapando dos modelos pré-estabelecidos e resistindo à pressão das expectativas impostas sobre eles, a fim do prazer de brincar e de ser feliz (Finco, 2010). 
Os meninos brincam com uma maior variedade de brincadeiras na rua do que as meninas. Elas, de acordo com os responsáveis, brincam mais de casinha, brincadeiras que acontecem predominantemente dentro de casa; enquanto que a maioria das atividades realizadas por eles requerem um ambiente externo. Conforme Jesus \& Furlan (2015) as brincadeiras das meninas condizem com o esperado para a feminilidade, de ter cuidados com a casa e com ambiente doméstico. Já as brincadeiras dos meninos remetem à autonomia, exploração do mundo exterior e liberdade.

Repara-se que embora as meninas e os meninos do estudo brinquem de faz-de-conta, os conteúdos das brincadeiras são diferentes, pois nesses momentos a estereotipia por gênero também se faz presente. As meninas brincam em maior extensão representando papéis que a sociedade considera como femininos - mais da metade delas $(n=6)$ costumam brincar de casinha, enquanto uma delas $(n=1)$ brinca também de escolinha. Nessas brincadeiras, tem-se principalmente a perpetuação da figura feminina nas atividades; as meninas costumam representar as funções domésticas, feitas pela mãe, ou as do ambiente escolar, feitas pela professora. Quanto aos meninos, apenas um deles $(n=1)$ costuma brincar de casinha. Eles preferem representar papéis mais agitados, que representem velocidade e força, quando brincam, por exemplo, com os brinquedos de carrinhos e bonecos.

Os jogos eletrônicos são brincadeiras que tanto as meninas $(n=3)$ quanto os meninos $(n=5)$ costumam brincar. Ressalta-se que nessa modalidade de jogos também existem as distinções por gênero, onde existem jogos virtuais exclusivos para meninas ou meninos, os quais reforçam as ideias de papéis sociais e de gêneros que cada sujeito deve ocupar. Conforme Machado \& Júnior (2013) os jogos virtuais limitam o brincar, já que possuem uma estrutura fechada de regras, valores e tarefas pré-determinadas, diminuindo consequentemente a possibilidade de imaginação da criança e propiciando que as reproduções de estereótipos aconteçam mais facilmente. Para os mesmos autores, Machado \& Júnior (2013: 98), os jogos dirigidos as meninas

reproduzem concepções discriminatórias que concebem a mulher enquanto ser frágil, que se preocupa apenas com sua estética pessoal e que têm as tarefas ou os espaços domésticos como suas especialidades. Assim, os jogos reafirmam papéis sociais que cada sexo deve "representar", constituindo a subjetividade dos sujeitos de forma a sustentar relações desiguais e injustas.

A dominação de estereótipos acontece de forma global em todo o site de jogos eletrônicos. A classificação dos jogos, que os distinguem em dois mundos diferentes, separa-os em de meninas e de meninos, as opções de atividades ofertadas nos jogos, as cores, a aparência e a música dos temas dos jogos são desiguais. Os jogos dirigidos para o público infantil feminino apresentam cores em tons de rosa, músicas suaves e clássicas e possuem seus temas voltados a maquiagem, moda, culinária e a maternidade (Araújo, 2017). Por outro lado, os jogos voltados para o público infantil masculino possuem cores em tons de azul, músicas agitadas e temas 
relacionados a carros, corrida, futebol e luta. Tendo isso em vista, imagina-se que os adultos permitam que as crianças escolham livremente os jogos que irão se divertir, sem a sua supervisão constante, logo, desconhecem o conteúdo de determinados jogos. Portanto, a influência dos estereótipos através dos jogos virtuais, por parte dos adultos, pode ocorrer de modo despretensioso.

Já nos primeiros anos de vida das crianças, os responsáveis presenteavam-nas com brinquedos cujas marcações de gênero foram bastantes típicas e evidentes.

Quadro 3- Distribuição dos brinquedos por gênero, anterior a pedidos das crianças.

\begin{tabular}{|c|c|c|c|}
\hline \multicolumn{2}{|c|}{ BRINQUEDOS QUE AS CRIANCS GANHAVAM (ANTES DE COMEÇAR A PEDIR) } \\
\hline MENINAS & TOTAL & MENINOS & TOTAL \\
\hline Bonecas & 8 & Brinquedos de Encaixe/Montar & 3 \\
\hline Brinquedos de Encaixe/Montar & 3 & Carrinhos & 3 \\
\hline Carrinho de Boneca & 2 & Livros & 1 \\
\hline Bichos de Pelúcia & 2 & Brinquedos de Borracha & 1 \\
\hline Panelinhas/Fogãozinho & 2 & Bola & 1 \\
\hline Chocalho & 1 & Bonecos & \\
\hline Maquiagem & 1 & & \\
\hline Bola & 1 & & 1 \\
\hline
\end{tabular}

Fonte: Elaborado pelas autoras, a partir das respostas dadas pelos responsáveis.

Percebe-se de forma nítida, que os brinquedos fornecidos às crianças, desde pequenas, diferem conforme elas sejam meninas ou meninos.

Ao presentear a criança com um brinquedo, além do objeto propriamente dito, entrega-se um conjunto de valores e intenções que já estão expressos nos produtos (Possapp, 2014). Quando a criança recebe de presente bonecas para cuidar e conjuntos de panelinhas e comidinhas para preparar, servir e dar as refeições, está sendo preparada para o gênero feminino - ser passiva, cuidadosa e bondosa - incentiva-se então que sejam boas cuidadoras do lar. Se a criança ganha carros, bolas, brinquedos de encaixe e montar, ou outros brinquedos que estimulem a competição e/ou que exigem esforços mentais e corporais incentiva-se a dominação do espaço público, fora do ambiente doméstico e familiar (Bento, 2008).

Os brinquedos disponibilizados pelos adultos às crianças possuem uma carga ideológica de significados de uma cultura que separa hierarquicamente homens e mulheres, atribuindo valores sociais dominantes. Eleger os brinquedos segundo o sexo, os pais, acabam por acionar valores socialmente definidos como masculino e feminino. Assim, podemos entender os brinquedos como um sistema de significados não apenas para aqueles que os utilizam, mas também para os que os difundem (Nascimento, 2014: 264). 
Segundo Barreto \& Silvestri (2006), ao passo em que as crianças se apropriam dos brinquedos ofertados pelos adultos, elas incorporam valores característicos como femininos e masculinos, reproduzindo-os; logo, introduzem as vivências de gênero de uma cultura que separa mulheres e homens, e como resultado aprendem precocemente a distinguir os papéis sociais diferentes e desiguais.

Desde bebês, as crianças aprendem que meninas brincam de bonecas e os meninos de carrinhos. De acordo com Kishimoto \& Ono (2008), precedentemente que as crianças comecem a fazer suas escolhas, os pais são os responsáveis por construir o primeiro ambiente de brinquedos que estarão disponíveis a elas. Ao nascer, o quarto das meninas já está decorado de rosa com bonecas de brinquedos e o dos meninos em azul, com miniaturas de carros. Quando questionado quais os tipos de brinquedos que os responsáveis costumavam comprar para as crianças nesta época, vários deles $(\mathrm{n}=10)$ citaram a compra de pelo menos um objeto típico quanto ao gênero; alguns ( $n=8)$ não falaram o motivo e outros $(n=2)$ justificaram a compra de tais objetos justamente pelo fato das crianças possuírem determinado gênero, o que pode ser ilustrado na seguinte fala:

“Bonecas, por ser menina." (P8)

Os adultos também podem comprar os brinquedos para as crianças e reforçar esses estereótipos de gênero de modo inconsciente, automático, naturalizado, impulsivo e/ou fechado, sem necessariamente realizarem a todo o momento alguma reflexão ou possuírem um pensamento elaborado a respeito dos objetos, simplesmente seguindo um padrão já pré-estabelecido pela sociedade, cultura, mídia e publicidade e por vivências na própria infância. Pode ser algo natural que carrinhos sejam brinquedos de meninos, que os adultos, por sua vez, gostam de presentear os filhos com esse objeto. $\mathrm{O}$ que é ilustrado abaixo, com a fala de uma mãe de menino:

“Carrinhos, porque eu gosto de dar carrinhos." (P16)

Percebe-se que as meninas estão imersas no mundo da beleza desde pequenas. Ao presenteá-las com maquiagens, elas aprendem que as mulheres necessitam ser providas de beleza. Assim sendo, Lira \& Nunes (2016) afirmam que os brinquedos do tipo kits de maquiagens contribuem para que as crianças se aflijam em se tornarem mulheres bonitas fisicamente e preocupadas com a aparência. Lamas (2016: 789) corrobora que ao receberem essa mensagem, as crianças constroem "um ideal de feminilidade que é baseado na aparência física, em um modelo extremamente exigente e rígido quanto ao corpo.” Mesmo antes de começar a pedir brinquedos, um dos pais já presenteava sua filha com conjuntos de maquiagens, devido ao fato dela ser uma menina, o que pode ser percebido na fala abaixo: 
"Boneca, maquiagem... Melhor dizendo, brinquedos de menina." $(\mathrm{P} 14)$

Segundo Kishimoto \& Ono (2008), raramente se encontram meninas que exploram carrinhos e meninos que exploram bonecas, devido ao fato de ao nascerem os pais já terem construído esse ambiente de brinquedos segregados por gênero. Dificilmente, encontramos nos quartos das meninas brinquedos como carrinhos de corrida e bonecos, bem como é incomum encontrar nos quartos dos meninos bonecas e produtos de beleza (Junges, 2014). Cruz et al. (2012) afirma que para fazer parte do universo feminino, os carros de brinquedos devem ser delicados, com cores em tons de rosa. Normalmente, o carro de brinquedo é pensado para os meninos; e o carro de menina não é pensado como um carro de menino. Constata-se que quando os brinquedos ditos como masculinos são utilizados pelas meninas, esses têm de ter traços femininos. O carrinho então não é apenas um carrinho, ele precisa ser meigo, ele é de boneca. Tal resultado pode ser ilustrado pela seguinte fala:

"Boneca, panelinha, carrinhos de boneca." (P11)

Alguns pais $(n=7)$ afirmaram acreditar que existem diferenças entre os brinquedos das crianças conforme o seu gênero, o que pode ser explicado, de acordo com eles, devido as meninas e meninos apresentarem preferências diferentes. As falas a seguir expõe determinada situação:

"Sim, bonecas sempre foram referência para meninas, não que os meninos não brinquem, o que acho muito normal, assim como carrinhos para meninos. Não acho que precise haver diferença, simplesmente sempre compro para minha filha bonecas porque são as escolhas dela." (P8)

"Sim, existe brinquedos de meninos e de meninas. Meninas gostam de bonecas, trocar roupas de bonecas, maquiagem, fazer 'comidinha', meninos gostam de carrinhos, bonecos. Sim, existe diferença sim, meninos não brincam com maquiagem e meninas dificilmente vão brincar de carrinhos." ( $\left.\mathrm{P}_{17}\right)$

Entretanto, é comum que muitas crianças ao escolherem algum brinquedo de presente, escolham os típicos ao seu gênero, pois, muitas vezes, elas "nem esperam que os pais lhes presenteiem, ou mesmo as permitam explorar brinquedos 'adequados' para o gênero oposto" - assim como existem pais que podem ignorar a vontade da criança em possuir determinado objeto (Junges, 2014: 49). Além disso, a mídia e a publicidade disseminam as informações que são absorvidas pela sociedade e, logo, perpetuadas pela cultura; como por exemplo, as diferenças entre meninas e meninos que são demarcadas pelos brinquedos - através dos objetos, das cores. Através 
desses produtos infantis, é transmitido que as crianças necessitam ser diferentes de acordo com o sexo que possuem e que devem gostar de coisas diferentes, ensinando comportamentos sexistas e desiguais. Tanto as crianças quanto os adultos aprendem o modelo que a sociedade espera de cada um (Possapp, 2014), e dessa maneira, mesmo crianças, já internalizam necessidade de escolhas diferentes.

Os meninos são mais cobrados pela sociedade acerca da necessidade de seus comportamentos corresponderem com o gênero que pertencem, quando comparados com as meninas (Bichara, 2011) e consequentemente, sofrem mais pressão para que seus brinquedos e brincadeiras correspondam com as expectativas do seu gênero. "Em especial, meninos são mais restritos no que se refere a apropriação de brinquedos e brincadeiras, pois pertencem ao polo dominante e mais valorizado, tornando mais fácil a apropriação do universo lúdico masculino pelas meninas" (Sant'anna, 2014: 26). O que pode ser identificado na fala de uma das mães, que ao perguntar se existia brinquedos diferentes de acordo com o gênero da criança, respondeu a existência de brinquedos que seriam exclusivos às meninas; brinquedos esses que não fariam parte do âmbito masculino.

“Existe brinquedo de menina." ( $\left.\mathrm{P}_{7}\right)$

Os pais propendem a afastar seus filhos a brincar com brinquedos considerados como típicos de meninas com mais afinco, do que as suas filhas a brincar com brinquedos típicos de menino (Junges, 2014). Por conseguinte, Pereira \& Oliveira (2016) relatam que vários meninos possuem vontade de brincar com bonecas, maquiagens ou com conjuntos de cozinha, porém são reprimidos, pois devem seguir à risca o padrão de gênero masculino, sem que exista, para eles, a possibilidade de transgressões. Uma das mães, ao responder positivamente que já havia pensado a respeito dos brinquedos e brincadeiras que são ofertados às crianças, complementa sua resposta, e diz perceber que os responsáveis de crianças do sexo masculino reduzem as opções dessas crianças com mais afinco do que os responsáveis de crianças do sexo feminino. Ademais, outra mãe falou nunca ter vivenciado problemas em relação aos brinquedos dos seus filhos. Porém, não demonstrou, por meio de sua escrita, nenhum sentimento de incômodo caso sua filha pedisse carrinhos, enquanto admite que acharia estranho caso o seu filho pedisse a ela maquiagens. Apesar de retratarem o assunto de modos diferentes, as duas escritas abaixo mostram, respectivamente, que os meninos possuem mais restrições do que as meninas.

"Já havia pensado, pois noto que os pais e mães de menino tem mais dificuldade nisso." ( $\left.\mathrm{P}_{1}\right)$

"Nunca tive esse problema com nenhum dos meus filhos. Mas acharia estranho se meu filho quisesse maquiagem, por exemplo. Mas carrinhos minha filha brinca, mas nunca me pediu." (P8) 
Haja vista, os responsáveis de meninos devem levar em consideração que brincar de bonecas proporciona benefícios às crianças: ora, representar os papéis sociais de mãe e pai intensificam as habilidades sociais e emocionais; ter cuidados para com outras pessoas pensando em suas necessidades e perceber seus sentimentos, desenvolverão a empatia, aspectos verbais e de comunicação (Eliot, 2013). Da mesma forma, os responsáveis de meninas também devem levar em consideração que brincar de carrinhos é importante para o desenvolvimento de habilidades como as de coordenação motora, agilidade e atenção (Junges, 2014). Logo, as brincadeiras "de meninas" ou "de meninos" são importantes para todas as crianças, independentemente se são meninas ou meninos.

Quando indagado se o responsável já deixou ou deixaria de comprar qualquer brinquedo considerado típico do gênero oposto para a criança, alguns responsáveis $(n=5)$ responderam positivamente. Para Bezerra \& Marques (2017), de modo sútil, os pais podem reforçar os estereótipos de gênero; há uma propensão maior dos pais comprarem bonecas para as meninas e carrinhos para os meninos, impondo assim, os objetos típicos por gêneros sem que façam necessariamente uma distinção verbal para as crianças. Em contrapartida, os pais também podem ser bastante explícitos quanto à segregação, falando de modo claro e direto para as crianças que existem brinquedos e brincadeiras de meninas e de meninos. Tais situações podem ser vistas, respectivamente, nas falas a seguir:

"Sim. De certa forma ainda estou presa em uma mentalidade ultrapassada, e não compraria uma boneca para o meu filho, simplesmente oferecendo um outro brinquedo, sem muitas justificativas plausíveis." $\left(\mathrm{P}_{3}\right)$

"Sim! Deixaria de comprar, eu iria explicar que aquele brinquedo não é de menino (a) e tentar convencer a criança a comprar um brinquedo apropriado para o gênero dela." ( $\left.\mathrm{P}_{17}\right)$

Posto isto, toda vez que os adultos segregam os brinquedos por sexo, classificando-os em brinquedos ou "de meninas" ou "de meninos", eles transmitem, de modo subliminar, irrefletido, ou mesmo convicto, suas crenças quanto ao gênero do brinquedo e da brincadeira, assim como os valores associados a este universo; ou seja, mostram para as crianças a mensagem de que elas são diferentes e como resultado devem brincar, ter atitudes e realizar papéis distintos, necessitando assumir a postura de mulher ou homem expressa pela sociedade. Eles desde cedo, delimitam os brinquedos que são destinados às meninas e aos meninos e designam os papéis hierárquicos entre as mulheres e homens (Nascimento, 2014).

As cores, assim como os brinquedos e brincadeiras, também estão atribuídas e são diferenciadas quanto aos gêneros. O rosa é típico como cor feminina e o azul como masculina, porém, antigamente acontecia o inverso; o azul era percebido preferencialmente como uma cor feminina e o rosa como uma cor masculina. 
Conforme Paoletti (1997, apud Fine, 2012) o rosa, por ser próximo da cor vermelha, caracterizava-se como uma cor decidida e forte, representando ardor e coragem, logo, era mais apropriado para os meninos; e o azul caracterizava-se por ser delicado e gracioso, sendo adequado para as meninas. A apropriação de cores rosa e azul para meninas e meninos, respectivamente, teve início somente a partir de 1920, quando se tornou possível a fabricação de roupas com cores resistentes à fervura, marcando a rotulação do rosa e azul por gêneros; e por volta de 1970 o rosa como cor feminina foi imposto internacionalmente (Heller, 2013).

Percebe-se que a cor rosa é exclusiva do universo feminino, embora esse universo também possa se apropriar, ocasionalmente, da cor azul. E ainda que universo masculino possua um repertório de cores mais amplo (ex.: azul, verde, preto, amarelo, etc.), a cor rosa não é uma opção para os meninos. "A cultura do rosa [...] é baseada no culto da beleza, do corpo, da aparência, da magreza, em detrimento da inteligência” (Golderberg, 2013: 76), e apenas as meninas estão aptas a fazer parte dessa cultura. Quando questionado sobre uma menina possuir um brinquedo na cor azul ou um menino possuir um na cor rosa, como uma bicicleta, por exemplo, poucos responsáveis $(n=3)$ afirmaram ter restrições em relações as cores, e apenas um deles $(n=1)$ relatou que não se impõe dependendo do tipo de brinquedo que seria dado. Chama-se a atenção, porém, que dentre os responsáveis que possuem restrições quanto as cores rosa e azul, uma mãe salientou que não há problemas em uma menina possuir um brinquedo (bicicleta) na cor azul, mas existe problemas em um menino ter uma na cor rosa, o que pode ser percebido na seguinte fala:

"O azul para menina, penso ser normal, mas o rosa para menino ainda causa um certo impacto. Não daria uma bicicleta rosa para um menino, mas uma azul para uma menina sim." $\left(\mathrm{P}_{3}\right)$

As meninas e meninos do estudo podem brincar juntos. Todos os responsáveis relataram não se importar se as meninas brincassem sozinhas em grupos de meninos e vice-versa. Ao brincar em grupos divididos por sexo, ou seja, grupos somente com crianças do sexo feminino ou masculino, as crianças aprendem e reforçam comportamentos tipificados, limitam a possibilidade de transgressões e, consequentemente, mantêm os estereótipos dos papéis sexuais. Logo, quando meninas brincam com meninos, elas tendem dispensar menos tempo em atividades exclusivas femininas; proporcionando, menos tempo de exposição a experiências unicamente tipificadas para o sexo feminino, e, consequentemente, menos rigidez de papéis e estereótipos de adequação e/ou inadequação de comportamentos (Silva et al., 2006), ocorrendo igualmente para os meninos.

Para a maior parte dos responsáveis $(n=11)$ as brincadeiras não determinam o futuro profissional e escolha de profissões das crianças na vida adulta. Bomtempo (1997, apud Cordazzo, 2003) afirma que para alguns adultos, o brincar não possui um papel significativo para as crianças, considerando-o apenas como passatempo 
e diversão. Entretanto, alguns autores como Rolim et al. (2008) e Maluf (2009) estabelecem que as brincadeiras são fundamentais para aquisição de aprendizados e para o desenvolvimento de habilidades. São atividades tão importantes que inclusive, contribuem na futura atuação profissional dos sujeitos. Pedroso (2011) e Lamas (2016) corroboram com tal informação e enfatizam que são capazes de proporcionar assimilação, por parte das crianças, dos diferentes papéis sociais que elas podem ocupar. Abaixo estão ilustradas falas em que os responsáveis representam determinada situação:

“Não, pois os brinquedos são para divertir." ( $\left.\mathrm{P}_{4}\right)$

"Acho que na infância tipos de brinquedos não determinam ou limitam opções na vida adulta.” (P8)

Considerando que as brincadeiras contribuem tanto para o desenvolvimento infantil, como para o desempenho de futuras ocupações, como o trabalho, e mostram papéis sociais diversos, é essencial que possamos oferecer brinquedos variados para meninas e meninos; e não somente aqueles estereotipados conforme o gênero, a fim de possibilitar as mesmas oportunidades para ambos.

Afinal, se ensinamos às meninas que elas devem ser boas donas de casa e aos meninos que eles devem conquistar o mundo, estabelecemos uma desigualdade muito grande nas possibilidades que se apresentam a cada gênero. Não que haja algo de errado em querer ser mãe, esposa, modelo de passarela, aventureiro, construtor de prédios ou lutador, mas restringir, já desde a infância, as opções de brincadeira - e, portanto, de sonho e de imaginação - de acordo com uma definição estereotipada de gênero é um problema, e um criado pelos adultos. (Lamas, 2016: 1005, grifo do autor).

Foi durante a pesquisa que alguns adultos $(n=5)$ atentaram a respeito dos brinquedos e das brincadeiras das crianças pela primeira vez. Em razão disso, levase a pensar que ao comprar um brinquedo, participar de brincadeiras ou apenas supervisioná-las, os responsáveis podem somente reproduzir o que aprenderam e vivenciaram ao longo do seu desenvolvimento. É muito "normal" existirem diferenças entre os brinquedos que são oferecidos para as meninas e para os meninos e distinções nos tipos de brincadeiras que elas costumam brincar, que é muito fácil esquecer-se de pensar a respeito sobre o tema. Assim, os adultos disseminam para as crianças a marcação de gêneros e papéis sociais que aprenderam com seus próprios pais durante o período da sua infância e ao longo da sua vida - pela sociedade, pela cultura, pela mídia pela publicidade -, e, caso não tenham oportunidades para refletir sobre, dificilmente irão questionar algo que aprenderam como sendo natural (Lamas, 2016). 
A fim de problematizar tais questões de gênero - presentes nos brinquedos e brincadeiras - e abordar a importância do brincar, é importante que o Terapeuta Ocupacional possa criar espaços reflexivos, com crianças, pais, responsáveis, educadores e demais profissionais da área pediátrica, para que tais assuntos sejam debatidos, pois, conforme Ferland (2002 apud Ferland, 2006) é papel do Terapeuta Ocupacional prevenir e promover a saúde de modo a proporcionar um desenvolvimento saudável, favorecer a relação entre pais e filhos e esclarecer para os pais a importância do brincar na infância. Desse modo, contrapor a ideia de que os brinquedos são somente objetos para passar o tempo e/ou divertir, bem como enfatizar que cada objeto carrega uma série de significados, os quais são absorvidos pelas crianças desde pequenas.

Os profissionais também são aptos a oferecer sugestões de brinquedos e brincadeiras para as crianças (Gauvin; Lefebvre, 2001 apud Ferland, 2006), propondo brinquedos diversificados para meninas e meninos, que propiciem objetivos variados (Silva, 2008) e favoreçam diferentes habilidades mentais, já que em brincadeiras tradicionais femininas e masculinas as crianças adquirem diferentes aprendizados (Eliot, 2013).

Para autores como Vianna \& Finco (2009), Finco (2010), Bicalho (2013) e Sousa et al. (2015), as crianças que contrariam os valores de gênero ditados pela sociedade [brincando com brinquedos considerados do gênero oposto] são passíveis de preconceitos sociais; e tais atitudes podem interferir de modo prejudicial na qualidade de vida dessas crianças.

Com o propósito de ampliar o repertório das opções de papéis e reduzir possíveis prejuízos no desempenho ocupacional dos indivíduos - tanto no período da infância quanto no adulto - o Terapeuta Ocupacional deve analisar os brinquedos, investigar as brincadeiras vivenciadas pelas crianças e intervir, caso necessário, no processo de apropriação e formação das identidades, com a finalidade de que as crianças tenham liberdade para criar a sua própria identidade (Bicalho, 2013), visto que a área de desempenho do brincar é um foco de intervenção desses profissionais (Carleto et al., 2010).

Também, para Monteiro et al. (2015), o profissional deve problematizar e criar estratégias para enfrentar e modificar as questões desiguais de gênero, que estão presentes tanto nos brinquedos como nas diferentes formas de brincar - e desconstruir os rótulos de gênero presente nos brinquedos e brincadeiras. Assim, o Terapeuta Ocupacional pode orientar, em sua prática, que não ocorram introduções de classificações de objetos por gênero, e ainda, pode propor momentos para pensar e/ou repensar as práticas de consumo e de ofertas de brinquedos e brincadeiras que são disponibilizados as crianças. Tais atitudes podem acontecer em seus diferentes contextos de atuação, tanto em atendimentos individuais e/ou em grupos (com crianças e/ou adultos), como em palestras, publicações e/ou congressos de eventos científicos. 


\section{Considerações finais}

Os participantes do estudo costumam escolher os brinquedos e as brincadeiras de acordo com o gênero das crianças. A influência de gênero pode ser consciente, informada, justificada, refletida, aberta e/ou inconsciente, naturalizada, reproduzida, fechada, automática e impulsiva. A primeira se dá quando os adultos, por acreditarem que existem diferenças entre meninas e meninos, delimitam intencionalmente os brinquedos e as brincadeiras - de modo explícito ou implícito. A segunda forma acontece quando os adultos através de suas atitudes, sem perceber ou refletir a respeito, propagam estereótipos de gênero (simplesmente) seguindo um padrão preestabelecido.

Mesmo muito jovens, as crianças entendem e internalizam os comportamentos dos adultos; aprendendo atitudes e papéis socialmente adequados para mulheres e homens. Os objetos e as atividades também estimulam habilidades cognitivas distintas. Por conseguinte, conforme os objetos e as atividades que vivenciam, as meninas e os meninos irão crescer acreditando serem díspares ou desiguais. Logo, as construções naturalizadas de gênero irão acarretar que as crianças se desenvolvam de modo a possuir habilidades e papéis sociais divergentes, bem como oportunidades desiguais.

Para combater tais diferenças, o Terapeuta Ocupacional pode ampliar o repertório de objetos que são ofertados às crianças e, assim, estimular diferentes habilidades e opções de papéis sociais minimizando possíveis prejuízos no desempenho ocupacional de meninas e meninos. É importante que o profissional crie espaços de debate, em seus contextos de atuação durante atendimentos individuais ou em grupos (ex.: contexto clínico, contexto escolar, contexto social, contexto hospitalar), bem como em palestras, publicações e congressos de eventos científicos, desconstruindo rótulos sobre os brinquedos "de meninas" e "de meninos" e preconceitos das questões de gênero; salientando que brincar com algo considerado do gênero oposto não influenciará na identidade de gênero e orientação sexual. Tais diálogos irão proporcionar diversas possibilidades de ser - independente do sexo - viabilizando a quebra de estereótipos, de dicotomias e de que orientações diferentes da heterossexual não sejam marginalizadas, perseguidas ou ignoradas, oportunizando que meninas e meninos possuam oportunidades iguais.

Apesar dos achados do estudo, e das pesquisadoras terem colocado a disposição para sanar possíveis dúvidas e questionamentos, pensa-se que algumas respostas podem ter sido mascaradas e/ou omitidas em função dos participantes não se sentirem em total confidencialidade (apesar de lhes ser garantido o direito a sigilo no TCLE). Além disso, alguns dados podem não ser totalmente confiáveis, pois os participantes estavam sujeitos a recorrer a demais pessoas ou a meios eletrônicos de pesquisa para responder as questões, em função do distanciamento com a pesquisadora. 


\section{Referências}

ARAÚJO, Antônia Edda; GALVÃO, Cláudia. (2014). "Desordens Neuromotoras". In: CAVALCANTI, Alessandra; GALVÃO, Cláudia (eds.). Terapia Ocupacional: Fundamentação e Prática. Rio de Janeiro: Guanabara Koogan, p. 328-337.

ARAÚJO, Jéssica Martins. (2017). "Estereótipos de gênero em jogos virtuais para meninas". In: SEMINÁRIO INTERNACIONAL FAZENDO GÊNERO 11 E 13 TH WOMEN'S WORLDS CONGRESS, Florianópolis - SC. Anais Eletrônicos do Seminário Internacional Fazendo Gênero 11 e 13th Women's Worlds Congress, Florianópolis, SC., 2017. Disponível em: <http://www.en.wwc2o17.eventos.dype.com.br/resources/ anais/1503666681_ARQUIVO_Modelo_Texto_completo_MM_FG(1).pdf $>$. Acesso em: 23 abr. 2018.

ARRUDA, Sérgio Luiz Saboya; LIMA, Manuela Caroline Ferreira. (2013). "O novo lugar do pai como cuidador da criança”. Rev. Estudos Interdisciplinares em Psicologia, Londrina, v.4, 2: p. 201-216, dez.

BARDIN, Laurence. (2016). Análise de Conteúdo. 2. ed. São Paulo: Edições 70.

BARRETO, Flavia O.; SILVESTRI, Monica Ledo. (2005). "Relações Dialógicas Interculturais: brinquedos e gênero". In: REUNIÃO ANUAL DA ANPED, 28a Caxambu-MG. Anais eletrônicos dos 40 anos da Pós-Graduação em Educação no Brasil. São Paulo: ANPED. Disponível em: <http://28reuniao.anped.org.br/textos/ ge23/ge23943int.pdf> Acesso em: 02 abr. 2018.

BENTO, Berenice. (2008). O que é transexualidade. 1. ed. São Paulo: Brasiliense.

BEZERRA, Danielly de Souza; MARQUES, Jefferson Antonio. (2017). "As influências na construção da identidade de gênero". Rev. de Pesquisa Interdisciplinar, Cajazeiras, v. 1, 2: p. 29-37.

BICALHO, Chaiton Whashington Cardoso. (2013). "Brincadeiras infantis e suas implicações na construção de identidades de gênero". Rev Med Minas Gerais, v. 23, 2: p.41-49.

BICHARA, Ilka Dias. (2001). "Brincadeiras de meninos e meninas: segregação e estereotipia em episódios de faz-de-conta”. Rev. Temas em Psicologia da SBP, n.1, 9: p.19-28.

BROUGÈRE, Gilles. (2010). Brinquedo e Cultura. 8. ed. São Paulo: Cortez. 
CARLETO, Daniel Gustavo Sousa; SOUZA, Alessandra Cavalcanti A.; SILVA, Marcelo; CRUZ, Daniel Marinho Cezar; ANDRADE, Valéria Sousa. (2010). "Estrutura da prática da terapia ocupacional: Domínio e processo - $2^{\circ}$ edição". Rev. Triang.: Ens. Pesq. Ext. Uberaba-MG, v. 3, 2: p.57-147, jul/dez.

CORDAZZO, Sheila Tatiana Duarte. (2003). Caracterização de brincadeiras de crianças em idade escolar. Dissertação (Mestrado em Psicologia) - Centro de Filosofia e Ciências Humanas, Universidade Federal de Santa Catarina, Florianópolis, SC. Disponível em: <http://www.scielo.br/scielo.php?pid=So102-79722008000300004\&script=sci_ abstract\&tlng=pt>. Acesso em: 27 set. 2017.

CRUZ, Lilian Moreira; SILVA, Zenilton Goldim; SOUZA, Marcos Lopes. (2012). "O brinquedo e a produção do gênero na educação infantil: uma análise pós-estruturalista”. In: SEMINÁRIO DE EDUCAÇÃO, DIVERSIDADE SEXUAL E DIREITOS HUMANOS, II, Vitória-ES. Anais eletrônicos do II Seminário Nacional de Educação, Diversidade Sexual e Direitos Humanos. Vitória-ES: Alexsandro Rodrigues. Disponível em: <http:// periodicos.ufes.br/gepss/article/view/3880>. Acesso em: 27 set. 2017.

ELIOT, Lise. (2013). Cérebro azul ou rosa: O impacto das diferenças de gênero na educação. 1. ed. Porto Alegre: Penso.

FERLAND, Francine. (2006). O modelo lúdico: o brincar, a criança com deficiência física e a terapia ocupacional. 3. ed. São Paulo: ROCA.

FERREIRA, Sueli Camargo. (1992). A indústria do brincar. Dissertação (Mestrado em Educação) - Instituto de Estudos Avançados em Educação, Fundação Getúlio Vargas, Rio de Janeiro, RJ.

FINCO, Daniela. (2010). "Brincadeiras, invenções e transgressões de gênero na educação infantil.” Revista Múltiplas Leituras, v. 3, 1: p.119-134, jan./jun.

FINE, Cordelia. (2012). Homens não são de Marte, mulheres não são de Vênus: como a nossa mente, a sociedade e o neurossexismo criam a diferença entre os sexos. 1. ed. São Paulo: Cultrix.

GOLDENBERG, Mirian. (2013). Homem não chora. Mulher não ri: 8o ideias para entender melhor sexo, amor e felicidade. 1. ed. Rio de Janeiro: Nova Fronteira.

HELLER, Eva. (2013). A psicologia das cores: como as cores afetam a emoção e a razão. 1. ed. São Paulo: Gustavo Gili. 
JESUS, Tatiane Dantas Silva; FURLAN, Cássia Cristina. (2015). "Gênero e livros infantis: Uma experiência com a história 'menino brinca de boneca?". In: SIMPÓSIO INTERNACIONAL DE EDUCAÇÃO SEXUAL: FEMINISMOS, IDENTIDADES DE GÊNERO E POLÍTICAS PÚBLICAS, IV, Maringá - PR. Anais eletrônicos do IV SIES. Maringá - PR: UEM, 2015. Disponível em: < http://www.sies.uem.br/ trabalhos/2015/627.pdf>. Acesso em: 17 abr. 2018.

JUNGES, Rafaela. (2014). Meninos que brincam com bonecas viram meninas? Diferenças de gênero nas brincadeiras de crianças de 4 a 5 anos. Dissertação (Trabalho de Conclusão de Curso em Pedagogia) - Faculdade de Pedagogia, Centro Universitário Univates, Lajeado, RS.

KISHIMOTO, Tizuko Morchida. (1994). “Jogo, brinquedo e brincadeira”. Rev. Perspectiva, Florianópolis, n. 22, 1: p. 105-128.

KISHIMOTO, Tizuko Morchida; ONO, Andréia Tiemi. (2008). "Brinquedo, gênero e educação na brinquedoteca”. Pro-Posições, v. 19, 3 (57): p. 209-222, set./dez.

LAMAS, Marília. (2016). De menina e de menino: infância e gênero [recurso eletrônico]. 1. ed. Rio de Janeiro: GWS.

LIRA, Aliandra Cristina Mesomo. (2009). "Brinquedo: História, cultura, indústria e educação”. Atos de Pesquisa em Educação, v. 4, 3: p.507 - 525, set./dez.

LIRA, Aliandra Cristina Mesomo; NUNES, Maristela Aparecida. (2016). "Ensinando a ser menina e menino: Brinquedos e relações de gênero”. Revista Ensino E Pesquisa, v.14, 1: p.18o - 200 jan./jun.

MALUF, Angela Cristina Munhoz. (2009). Brincar: prazer a aprendizado. 7. ed. Petrópolis, Rio de Janeiro: Vozes.

MARTINI, Giovana. (2010). O brincar na clínica da terapia ocupacional com crianças com deficiência física: relato de um caso. Rev. CETO, v. 12, 12: p.27- 31.

MONTEIRO, Rosana Juliet Silva; GONTIJO, Daniela Tavares; FACUNDES, Vera Lúcia Dutra; VASCONCELOS, Ana Carolina Sena. (2015). "Pensando comoum meninoé mais fácil: construções sobre as relações de gênero no discurso de meninas adolescentes”. Rev Ter Ocup Univ São Paulo, v. 26, 2: p. 207-215, mai./ago.

NASCIMENTO, Antônia Camíla de Oliveira. (2014). "Divisão sexual dos brinquedos infantis: uma reprodução da ideologia patriarcal”. Rev. O social em questão, v. 17, 32: p. 257-276. 
PEREIRA, A. S.; OLIVEIRA, E. M. B. (2016). "Brincadeiras de meninos e meninas. Cenas de gênero na educação infantil”. Rev. Reflexão e Ação, Santa Cruz do Sul, v. 24, 1: p. 273-288, jan./abr.

PEDROSO, Tamires Regina. (2011). Relação de Gênero: Abordando as diferenças em brincadeiras entre meninos e meninas. Dissertação (Trabalho de Conclusão de Curso em Pedagogia) - Faculdade de Pedagogia, Centro Universitário Municipal de São José, São José.

POSSAPP, Laura Torres. (2014). Lojas virtuais de brinquedos: gênero e mercadorização do brincar. Dissertação (Graduação em Pedagogia) - Faculdade de Educação, Universidade Federal do Rio Grande do Sul, Porto Alegre, RS.

ROLIM, Amanda Alencar Machado; GUERRA, Siena Sales Freitas; TASSIGNY, Mônica Mota. (2008). "Uma leitura de Vygotsky sobre o brincar na aprendizagem e no desenvolvimento infantil”. Rev. Humanidades, v. 23, 2: p. 176-18o, jul./dez.

SANT'ANNA, Luiza Moucachen. (2014).Além do azul e rosa-Papéis culturais de gênero em brinquedos e revistas dirigidos à criança. Dissertação (Trabalho de Conclusão de Curso em Licenciatura em Ciências Biológicas) - Universidade Federal do Rio Grande do Sul, Porto Alegre, RS.

SANTOS, Camila A.; MARQUES, Eliane M.; PFEIFER, Luiza Iara. (2006). "A brinquedoteca sob a visão da Terapia Ocupacional: Diferentes contextos". Cad Ter Ocup da UFSCar, v. 14, 2: p. 91-102.

SILVA, Elaine Soares. (2008). A relação entre a mídia e a escolha do brinquedo pela criança. Dissertação (Graduação em Pedagogia) - Faculdade de Educação, Universidade do Estado do Rio de Janeiro, Rio de Janeiro, RJ.

SILVA, Lúcia Isabel da Conceição; PONTES, Fernando Augusto Ramos; SILVA, Sarah Danielle Baia; MAGALHÃES, Celina Maria Colino; BICHARA, Ilka Dias. (2006). "Diferenças de gêneros nos grupos de brincadeiras na rua: a hipótese da aproximação unilateral". Rev. Psicologia: Reflexão e Crítica, v. 19, 1: p. 114-121.

SILVA, Matheus Estevão Ferreira; BRABO, Tânia Suely Antonelli Marcelino. (2016). "A introdução dos papéis de gênero na infância: Brinquedo de menina e/ou menino?" Trama Interdisciplinar, São Paulo, v. 7, 3: p. 127-140, set./dez. 
SOUSA, Maria Inês de Oliveira; ARAUJO, João Berkson da Rocha; ASTIGARRA, Andrea Abreu. (2015). “O 'sexo' dos brinquedos: Gênero na educação infantil”. In: CONGRESSO NACIONAL DE EDUCAÇÃO - CONEDU, II, Campina Grande PB. Anais eletrônicos do II Congresso Nacional de Educação - CONEDU. Campina Grande-PB: Editora Realize. Disponível em: <http://www.editorarealize.com.br/ revistas/conedu/trabalhos/TRABALHO_EVo45_MD1_SA11_ID8757_09092015140051. pdf>. Acesso em: 28 set. 2017.

ZEN, Camila Cristiane; OMAIRI, Claudia. (2009). O modelo lúdico: uma nova visão do brincar para a terapia ocupacional. Cad Ter Ocup UFSCar, v. 17, 1: 43- 51. 